\title{
Trichomes Morphology and Essential Oils Characterization of Field-Growing and In Vitro Propagated Plants of Lavandula pedunculata
}

\author{
M. Zuzarte ${ }^{* * *}$, A. M. Dinis ${ }^{* * *}$, C. Cavaleiro ${ }^{* *}$, J. Canhoto $^{* * * *}$ and L. Salgueiro ${ }^{* *}$ \\ *Dep. of Botany, Faculty of Sciences and Technology, Calçada Martim de Freitas 3001-455 \\ Coimbra, Univ. of Coimbra, Portugal. \\ ** Lab. of Pharmacognosy/CEF, Fac. of Pharmacy, Rua do Norte 3000-295 Coimbra, Univ. of \\ Coimbra, Portugal.
}

The selection of native Lavandula species and their economic exploitation have increased in the last few years. Micropropagation techniques have been used as an alternative for vegetative propagation allowing the multiplication of selected genotypes and chemotypes. Our previous studies showed that the essential oils of Lavandula pedunculata have an important antifungal activity against dermatophyte strains [1]. Therefore, a new line of investigation concerning the in vitro culture of this species is justified. In the present study we compare the morphology of the leaf trichomes and the chemical composition of their essential oils in both field-growing and in vitro propagated plants.

In vitro cultures of axillary buds of L. pedunculata were established in Murashige and Skoog medium (MS) supplemented with $0.25 \mathrm{mg} / \mathrm{L}$ BA (benzyladenine) and $10 \mathrm{mg} / \mathrm{L}$ ascorbic acid. Leaf trichomes were examined using scanning electron microscopy (SEM). The essential oils from both the aerial parts of field-growing plants and the rooted plantlets kept in vitro during 1 month were isolated by hydrodistillation and analysed by gas chromatography and gas chromatography/mass spectroscopy.

In vitro cultures (Fig. 1) were established with a success of $84.5 \%$. After 18 days in culture, an average of $4.07 \pm 0.35$ shoots per explant with more than $0.5 \mathrm{~cm}$ in length were obtained. Shoots were then separated and transferred to MS medium. After a month in culture an increase of $1.91 \pm$ $0.20 \mathrm{~cm}$ was observed, with an average number of $5.04 \pm 0.52$ nodes per plantlet. In this medium, $62.8 \%$ of the shoots rooted spontaneously avoiding the use of another medium and allowing a considerable gain in time of the regeneration process. SEM examinations showed that both the in vivo and in vitro samples presented three types of glandular trichomes: peltate (Fig. 2A), capitate type I (Fig. 2B), and capitate type II(Fig.2C) and a "mixed" type of trichomes (Fig.2D) with characteristics of both glandular and non-glandular ones. Nevertheless, the in vitro samples showed fewer glandular trichomes and the non-glandular ones were smaller and in lower number (cf. Fig $2 \mathrm{~F}$ and $2 \mathrm{G}$ ). The essential oils of the in vitro plantlets consisted of the same main components as the original field-growing parent (fenchone, 1,8-cineole, and camphor) and presented no remarkable compositional variations (Table 1).

Our study shows that the essential oils of in vitro propagated plantlets of $L$. pedunculata have a similar composition to those isolated from field-growing plants. Therefore, micropropagation through axillary shoot proliferation is a reliable method for the rapid multiplication of this species allowing essential oil production in any time of the year. This will be of value in plant conservation without damage of the natural resources. 


\section{Reference}

[1] M. Zuzarte, A.M. Dinis, C. Cavaleiro, J. Canhoto, M.J. Gonçalves, L. Salgueiro. 2007, II Encontro Nacional de Pós-graduação em Ciências Biológicas, Porto, pp 37.

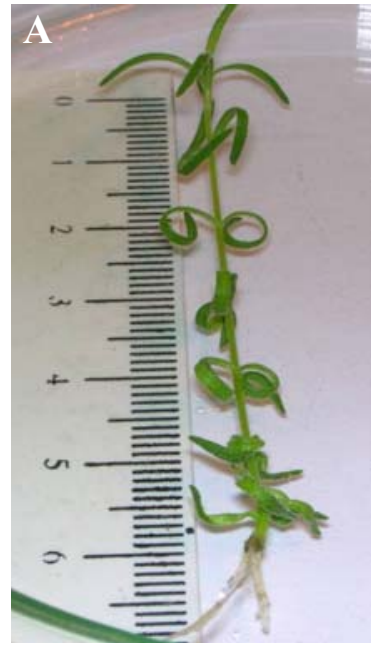

Fig. 1. In vitro plantlet of L. pedunculata after 18 days in culture.
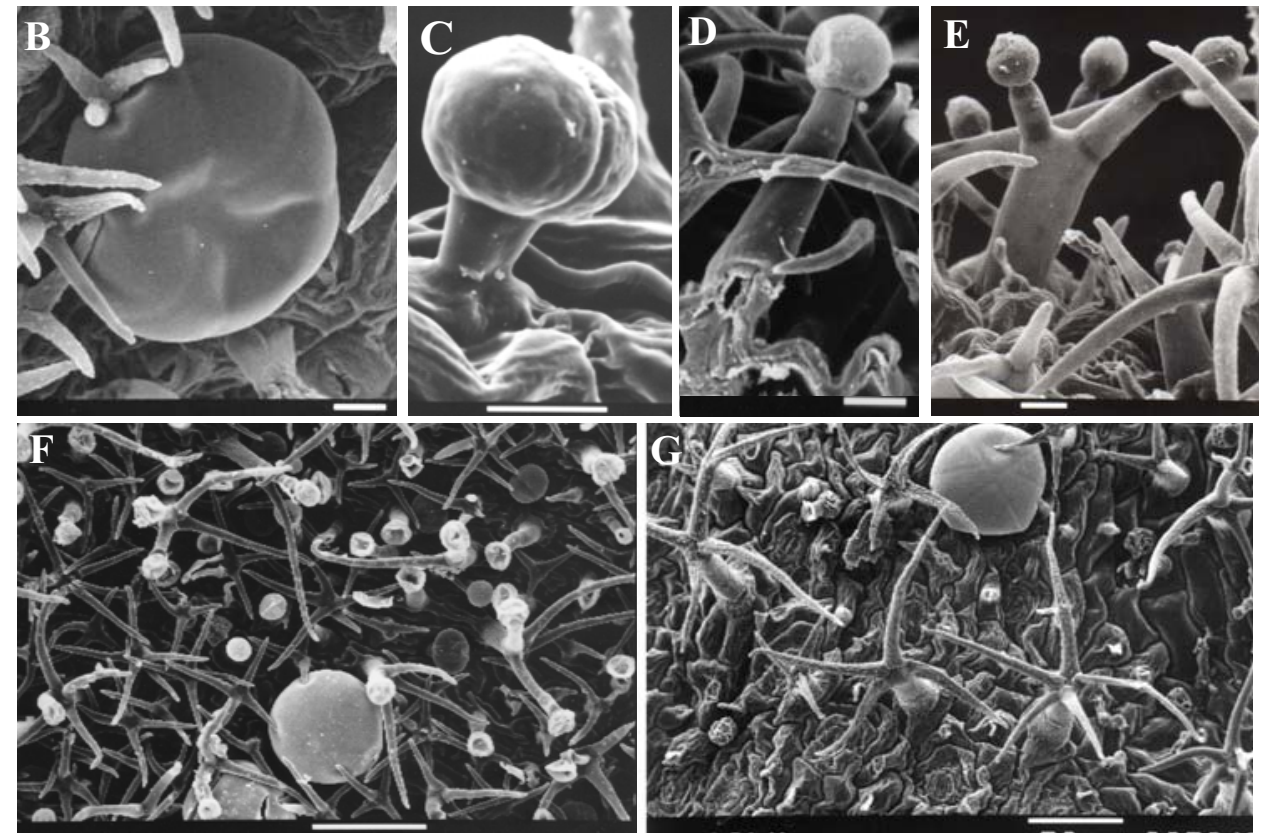

Fig. 2. SEM micrographs of L. pedunculata leaf trichomes. A. Peltate trichome. B. Capitate type I trichome C. Capitate type II trichome. D."Mixed" type trichome. Scale bars $=10 \mu \mathrm{m}$ F. Leaf adaxial surface of a field-growing plant. G. Leaf adaxial surface of an in vitro plantlet. Scale bars $=50 \mu \mathrm{m}$

TABLE 1. Essential oil composition (\%) of L. pedunculata isolated from a field-growing plant and the respective in vitro shoot cultures.

\begin{tabular}{|lll|}
\hline Compounds & Field-growing & In vitro \\
\hline$\alpha$-pinene & 8.6 & 7.4 \\
camphene & 3 & 1.9 \\
B-pinene & 1.8 & 7.1 \\
limonene & 3 & 5 \\
1,8-cineole & $\mathbf{9 . 8}$ & $\mathbf{7 . 1}$ \\
fenchone & $\mathbf{4 8 . 6}$ & $\mathbf{3 4}$ \\
linalol & 1.8 & 3.5 \\
$\alpha$-fenchol & 1.2 & 3 \\
camphor & $\mathbf{1 4 . 1}$ & $\mathbf{7 . 2}$ \\
cis-verbenol & 0.7 & 2.1 \\
trans-verbenol & 0.4 & 1.1 \\
borneol & 1.3 & $\mathrm{t}$ \\
terpineol-4 & 0.7 & $\mathrm{t}$ \\
myrtenal & 0.7 & $\mathrm{t}$ \\
bornyl acetate & 1.7 & $\mathrm{t}$ \\
$\alpha$-cadinol & 0.5 & $\mathrm{t}$ \\
Monoterpene hydrocarbons & 16.4 & 21.4 \\
Oxygen-containing monoterpenes & 81 & 58 \\
Oxygen-containing sesquiterpenes & 0.5 & $\mathrm{t}$ \\
\hline
\end{tabular}

$\mathrm{t}-\operatorname{traces}(<0.05 \%)$ 